\title{
Characteristics of offspring derived from conventional and X-sorted bovine sperm
}

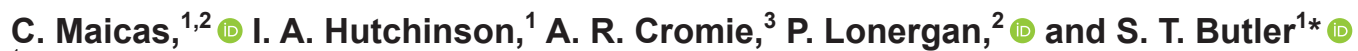 \\ ${ }^{1}$ Teagasc, Animal and Grassland Research and Innovation Centre, Moorepark, Fermoy, Co. Cork, Ireland P61 C996 \\ ${ }^{2}$ School of Agriculture and Food Science, University College Dublin, Dublin, Ireland D04 N2E5 \\ ${ }^{3}$ Irish Cattle Breeding Federation, Highfield House, Shinagh, Bandon, Co. Cork, Ireland P72 X050
}

\section{ABSTRACT}

The objective of this retrospective study was to compare survival during the first year of life and adult performance of offspring derived from artificial insemination (AI) with X-sorted or conventional sperm processed from the same ejaculates. We analyzed a data set that included AI of dairy heifers and lactating cows with fresh conventional sperm $\left(3 \times 10^{6}\right.$ sperm per straw), fresh X-sorted sperm ( 1 or $2 \times 10^{6}$ sperm per straw), or frozen $\mathrm{X}$-sorted sperm $\left(2 \times 10^{6}\right.$ sperm per straw). The data set contained records of 5,179 offspring born on 396 farms. Offspring were classified as born from conventional sperm (CONV) if they were the product of an insemination with fresh conventional sperm, or born from X-sorted sperm (SS) if they were product of any of the $3 \mathrm{X}$-sorted sperm treatments. Generalized linear mixed models were used to evaluate the effect of sperm treatment on (1) survival during the first year of life; (2) reproductive performance, lactation performance, and survival of female offspring; and (3) slaughter characteristics of male offspring. Stillbirth rates and mortality rates during the first 2 mo of life were greater for male calves $(2.8$ and $5.0 \%$, respectively) than for female calves (1.6 and 2.0\%, respectively). No differences between offspring derived from SS and CONV were detected for incidences of stillbirth or mortality during the first 12 mo of life within sex of calf. Reproductive performance, milk volume, milk fat, milk protein yields during first; second; and third lactations, and survival to third lactation did not differ between female offspring derived from CONV and SS. Across all age groups, CONV steers had heavier carcasses than SS steers ( 325.3 vs. $318.3 \mathrm{~kg}$ ), but there were no differences in weight between CONV and SS steers within any of the age groups $(\leq 24,25-27,28-30$, and $>30$ mo of

Received January 8, 2020.

Accepted March 27, 2020.

*Corresponding author: stephen.butler@teagasc.ie age). The distribution of slaughter age did not differ between CONV and SS steers when the analysis was restricted to herds that reared steers derived from both types of sperm. Carcass conformation and fat scores of steers were not affected by sperm treatment. There was no difference in carcass weight between young bulls $(\leq 2$ yr) derived from CONV or SS. In conclusion, the results provide no evidence of differences in survival during the first year of life between offspring derived from CONV or SS, or for any of the reproductive and lactation performance characteristics studied between female offspring derived from CONV or SS. Modest differences in carcass weight between CONV and SS steers were detected, but this may reflect differences in management and husbandry in the rearing herds rather than the sex-sorting process. A controlled study using steers derived from conventional or X-sorted sperm from split ejaculates and reared under the same husbandry conditions is needed to clarify whether there is a true difference in body weight gain due to the sexsorting process.

Key words: sexed semen, dairy cattle, offspring phenotype

\section{INTRODUCTION}

Multiple assisted reproduction technologies are available to dairy cattle breeders, ranging from established technologies, such as AI and multiple ovulation embryo transfer (MOET), to newer and emerging technologies, including in vitro embryo production (IVP), sex-sorted sperm, cloning, and gene editing. Many of these techniques have been associated with alterations to embryo phenotypes, and in some cases have been associated with alterations in fetal and offspring development (Farin et al., 2006; Duranthon and Chavatte-Palmer, 2018; Ramos-Ibeas et al., 2019). There is a paucity of data in the literature related to the health and longevity of bovine offspring produced using these techniques; for example, despite the transfer of $>1$ million bovine embryos produced by MOET and IVP annually (Viana 
et al., 2018), few studies have examined the health and production characteristics of these animals.

In cattle, X-chromosome-bearing sperm are larger and carry around $4 \%$ more DNA than Y-chromosomebearing sperm (Garner et al., 1983). Currently, bovine sex-sorted sperm is commercially produced using flow cytometric sex-sorting technologies that identify and sort $\mathrm{X}$ - and Y-bearing sperm based on this difference in sperm DNA content (Garner et al., 2013; Vishwanath and Moreno, 2018). Sex-sorted sperm is of particular relevance in dairy cattle breeding, where straws containing $\sim 90 \%$ X-chromosome bearing sperm (X-sorted sperm) are used to increase the proportion of female calves born after AI. Despite representing a smaller percentage of the AI market than conventional (i.e., unsorted) sperm, the use of X-sorted sperm is steadily increasing; for example, the use of X-sorted sperm in Holstein heifers in the United States increased from 9\% in 2007 to $31 \%$ in 2015 (Hutchison and Bickhart, 2016).

Although the number of calves derived from X-sorted sperm is increasing, few follow-up studies have investigated whether sex sorting has consequences for calf and adult characteristics, and these studies have reported contrasting results. While some studies have reported no differences between calves produced after AI with $\mathrm{X}$-sorted sperm or conventional sperm (Tubman et al., 2004; Borchersen and Peacock, 2009), others have reported a trend for a greater incidence of stillbirths among male calves after AI of nulliparous dams with X-sorted sperm (DeJarnette et al., 2009; Chebel et al., 2010; Norman et al., 2010; Healy et al., 2013). In addition, greater mortality rates (abortions at $\geq 180 \mathrm{~d}$ of gestation and neonatal death of calves $<7 \mathrm{~d}$ of age) have also been reported for male calves derived from insemination with X-sorted sperm after MOET (Mikkola et al., 2015).

In a retrospective study evaluating survival, growth, and production traits of offspring derived from 1 of 4 different assisted reproductive technologies on a single large dairy farm in Florida, Siqueira et al. (2017) reported that offspring derived from IVP with reverse $\mathrm{X}$-sorted sperm had greater cumulative mortality from 90 to $180 \mathrm{~d}$ of age, and produced less milk, fat, and protein in their first lactation compared with offspring from AI with conventional sperm. More recently, in an experiment evaluating the effects of intrauterine infusion of seminal plasma $(0.5 \mathrm{~mL})$ at the time of AI on pregnancy success of Holstein cows, Ortiz et al. (2019) found that seminal plasma infusion increased the birth weight of heifer calves born using X-sorted sperm, but not conventional sperm.

If the previous reports of an effect of X-sorted sperm on male calf mortality are true, it may present a welfare concern, but the economic impact is likely to be small, as only $10 \%$ of the offspring are male when $\mathrm{X}$-sorted sperm is used. However, a detrimental effect on adult performance of offspring derived from X-sorted sperm, especially if female offspring are affected, could negate the advantages of biased offspring sex ratio, and may reduce the adoption of $\mathrm{X}$-sorted sperm by the dairy industry.

We have previously reported the results of a large field trial evaluating the fertility of both conventional and X-sorted sperm processed from the same ejaculates (Maicas et al., 2019). Here, we present a retrospective study of the offspring that were born following that trial. We tested the hypothesis that calf survival and adult performance were not different between animals derived from AI with X-sorted or conventional sperm.

\section{MATERIALS AND METHODS}

\section{Data Source and Handling}

The data analyzed in this study relate to calves born following insemination of dairy heifers and lactating cows with conventional or X-sorted sperm in a field trial carried out in Ireland during the 2013 breeding season. Specific details regarding semen collection and processing, distribution of straws, and recording of inseminations were reported by Maicas et al. (2019). Briefly, ejaculates from Holstein bulls were collected and each ejaculate was split into 2 aliquots; one aliquot was processed to provide straws of fresh conventional sperm, whereas the second aliquot was sex-sorted for X-chromosome bearing sperm (X-sorted sperm) with a $90 \%$ bias using SexedULTRA sorting technology (Sexing Technologies, Navasota, TX). The fresh conventional straws contained $3 \times 10^{6}$ sperm per straw, and the $\mathrm{X}$-sorted straws were processed as either fresh $\left(1 \times 10^{6}\right.$ or $2 \times 10^{6}$ sperm per straw $)$ or frozen straws $\left(2 \times 10^{6}\right.$ sperm per straw). Straws were used to inseminate heifers and lactating cows on 492 farms from April 15 to May 18, 2013. Information about the offspring of these inseminations was retrieved from the Irish Cattle Breeding Federation database (www.ibcf .com), which is a repository for animal records, events, and performance data for all of the cattle registered in Ireland and the herds in which they reside. Data were merged in a unique data set and checked for duplicates, outliers, and invalid values, which were removed when appropriate. Only calves that were offspring of the conventional and X-sorted AI straws included in the final analysis of the study reported by Maicas et al. (2019) were retained for analysis (10 bulls; $172-721$ calves per bull). After merging and cleaning steps, the data set contained records for 5,179 offspring born on 396 farms. Of these, 846 female and 784 male calves were derived 
from fresh conventional straws, 1,075 female and 120 male calves were derived from fresh $\mathrm{X}$-sorted straws at $1 \times 10^{6}$ sperm per straw, 1,095 female and 124 male calves were derived from X-sorted straws at $2 \times 10^{6}$ sperm per straw, and 1,033 female and 102 male calves were derived from frozen $\mathrm{X}$-sorted straws. All calves were born between January 13 and March 6, 2014.

\section{Data Handling and Statistical Analysis}

To examine the possibility that differences existed between the $3 \mathrm{X}$-sorted sperm treatments, all data analyses were initially conducted using all 4 sperm treatments (fresh conventional, fresh $\mathrm{X}$-sorted at $1 \times$ $10^{6}$ sperm per straw, fresh $\mathrm{X}$-sorted at $2 \times 10^{6}$ sperm per straw, and frozen $\mathrm{X}$-sorted at $2 \times 10^{6}$ sperm per straw). Then, animals were classified as calves derived from conventional sperm (CONV) if they were the product of an insemination with fresh conventional sperm, or as calves born from X-sorted sperm (SS) if they were the product of any of the $3 \mathrm{X}$-sorted sperm treatments, and every analysis was repeated.

Results are reported as least squares means (LSM) and $95 \%$ confidence interval. A significant difference or effect was considered to exist when $P<0.05$.

Mortality Rates and Survival Analysis During the First Year. The analysis of mortality rates was restricted to the first year of life. Animals with a record for age at death during the first year of life (age at death $\leq 365 \mathrm{~d}$ ), but without slaughter data, were assumed to have died on-farm $(\mathrm{n}=351)$, while the remaining animals were considered to have remained alive during that first year. Generalized linear mixed models (PROC GLIMMIX, SAS 9.4, SAS Institute Inc., Cary, NC) for data with a binary distribution were used to evaluate differences between offspring derived from CONV and SS for stillbirth rates (stillborn calves were defined as those born dead or that died within 48 $\mathrm{h}$ after calving), mortality rates during the first 2 mo (excluding stillborn), and mortality rates from 3 to 12 mo of age. Bull, sperm treatment (CONV vs. SS), sex of the offspring (female vs. male), and the interaction between sperm treatment and sex of the offspring were included as fixed effects; herd where the offspring was born was included as random effect. Comparisons of LSM were performed using Tukey-Kramer adjustment for multiple comparisons.

The effect of sperm treatment on the interval from birth to death (age at death) was evaluated by the LIFETEST procedure in SAS using Kaplan-Meier analysis for female offspring that died during the first 2 mo of life $(\mathrm{n}=181)$ or during their first year $(\mathrm{n}=$ 236), and for male offspring that died during the first 2 mo of life $(\mathrm{n}=96)$ or during their first year $(\mathrm{n}=$
115). Kaplan-Meier plots were generated and logrank test was used to compare the survival distributions of offspring derived from SS versus CONV.

Reproductive Performance of Female Offspring. The use of AI in seasonal dairy herds is generally confined to the first 6 wk of a 12 -wk breeding season, usually starting between late April and early May. For the purposes of the analysis of reproductive traits, mating start date (MSD) was set as May 1. For the dichotomous variables (e.g., calved before vs. after MSD), generalized linear mixed models were used for data with a binary distribution to evaluate differences between female offspring derived from CONV and SS. For the continuous variables (i.e., age at first calving, calving interval), normality of residuals was checked, data were transformed when necessary, and generalized linear mixed models were used for data with a normal distribution to evaluate differences between female offspring derived from CONV and SS. Sperm treatment, bull, and the interaction between sperm treatment and bull were included as fixed effects, and herd at calving was included as random effect. Comparisons of LSM were performed using Tukey-Kramer adjustment.

Lactation Performance of Female Offspring. The normality of residuals was checked, data were transformed when necessary and generalized linear mixed models for data with a normal distribution were used to evaluate differences in milk, fat, and protein yields for first, second, and third lactation between female offspring derived from CONV and SS. Sperm treatment, bull, and the interaction between sperm treatment and bull were included as fixed effects, and herd where lactation performance was recorded was included as a random effect. Comparisons of LSM were performed using Tukey-Kramer adjustment.

Survival Analysis of Female Offspring that Calved at Least Once. The effect of sperm treatment on the lifetime survival of female offspring that calved at least once was evaluated by comparing the interval from birth to death (survival age) using the LIFETEST procedure in SAS with Kaplan-Meier analysis. Only female offspring that had at least one calving record were included in this analysis $(\mathrm{n}=3,472)$. Survival age was the age at death or slaughter for female offspring that were dead at the time of data retrieval (9/11/2019); female offspring that were still alive were right-censored, and their survival age was their age at time of data retrieval. Kaplan-Meier plots were generated and logrank test was used to compare the survival distributions of female offspring derived from SS versus CONV.

Weight at Slaughter of Steers and Young Bulls. Slaughter data were not available from male offspring that died on-farm, were exported, or when slaughter data were not provided to the Irish Cattle Breeding 
Federation. Of the 1,130 male calves that were born, slaughter data was available for 642 , and these were classified as bulls (age $>730 \mathrm{~d} ; \mathrm{n}=30$ ), young bulls (age $\leq 730 \mathrm{~d} ; \mathrm{n}=139)$, or steers $(\mathrm{n}=473)$ at slaughter. Male offspring classified as bulls were not included in further analysis due to the small number of animal records. Young bulls and steers were analyzed separately. Steers were grouped by age into 4 categories at slaughter: $\leq 24,25$ to 27,28 to 30 , and $>30$ mo of age. Young bulls were grouped by age into 2 categories at slaughter: $\leq 20$ and $\geq 21$ mo of age. The normality of residuals was checked, and we used generalized linear mixed models for data with a normal distribution. Sperm treatment, age category, and the interaction between them were included as fixed effects; the last herd where steers or young bulls were located before being sent to slaughter ( $\mathrm{n}=278$ and $\mathrm{n}=74$, respectively) was included as a random effect. Comparisons of LSM were performed using Tukey-Kramer adjustment. Not every herd at slaughter had reared both CONV and SS steers; therefore, we repeated the analysis of carcass weight of steers with only those herds that had reared at least $1 \mathrm{CONV}$ steer and $1 \mathrm{SS}$ steer $(\mathrm{n}=56$; total number of steers $=193$ ). Similarly, we repeated the analysis of carcass weight of young bulls with only those herds that had reared at least 1 CONV young bull and 1 SS young bull $(\mathrm{n}=13$; total number of young bulls $=50)$.

Age at Slaughter of Steers. The effect of sperm treatment on the interval from birth to slaughter (age at slaughter $)$ of steers $(\mathrm{n}=473)$ was evaluated by the LIFETEST procedure in SAS using Kaplan-Meier analysis. The last herd where steers were located before being sent to slaughter was considered as herd at slaughter $(\mathrm{n}=278)$. Not every herd at slaughter had both CONV and SS steers, and thus the analysis was repeated with only those herds that had steers of both types $(\mathrm{n}=56$; total number of steers $=193)$.

Carcass Conformation and Fat Scores of Steers. Carcasses were classified at slaughter based on a visual assessment of carcass conformation and fat content according to EU scales (EU, 2013) into 1 of 9 conformation classes $(\mathrm{P}-, \mathrm{P}=, \mathrm{P}+, \mathrm{O}-, \mathrm{O}=, \mathrm{O}+$, $\mathrm{R}-, \mathrm{R}=, \mathrm{R}+$ ) that were coded 1 to 9 from the poorest $(\mathrm{P}-)$ to the best $(\mathrm{R}+)$, and 1 of 5 fat classes that were coded 1 to 5 from the least fat score (1) to the greatest fat score (5). For multinomial models, we used PROC GLIMMIX in SAS with adaptive quadrature method to evaluate the effect of sperm treatment and age at slaughter on carcass conformation and fat scores. Carcass conformation scores $\geq 4$ were defined as high conformation, and those $<4$ as low conformation. Similarly, fat scores $\geq 3$ were defined as high fat and those $<3$ as low fat. Using the generalized linear mixed model for data with a binary distribution, with sperm treatment and slaughter weight category as fixed effects, odds ratios for high conformation and high fat scores due to the sperm treatment were calculated. The last herd where the steer was located before being sent to slaughter was included as random effect in both multinomial and binary models.

\section{RESULTS}

\section{Analysis of Differences Without Grouping Sex-Sorted Treatments}

There was no evidence of differences between female offspring derived from each individual sperm treatment for any of the mortality, reproduction, and milk production variables (for all variables $P>0.16$; Supplemental Table S1, https://doi.org/10.3168/jds.2020-18178) or survival distributions (logrank test: for all variables $P$ $>0.13$; Supplemental Figures S1 and S2, https://doi. org/10.3168/jds.2020-18178). Similarly, neither mortality rates and carcass characteristics $(P>0.21$; Supplemental Table S2, https://doi.org/10.3168/jds.2020 -18178) nor survival distributions (logrank test: for all variables $P>0.67$; Supplemental Figure S3, https:/ /doi.org/10.3168/jds.2020-18178) differed between male offspring derived from each individual sperm treatment. The distribution of slaughter age differed (logrank test: $P=0.03$ ) between steers derived from each individual sperm treatment when every herd was included in the analysis, but it did not differ (logrank test: $P=0.84$ ) when the analysis was restricted to only herds that had reared at least $1 \mathrm{CONV}$ steer and 1 SS steer (Supplemental Figure S4, https://doi.org/10 .3168/jds.2020-18178). Hence, the 3 SS treatments were combined to provide a more strongly powered appraisal of differences between SS and CONV treatments.

\section{Mortality Rates and Survival Analysis for the First Year of Life}

Stillbirth rates were greater for male offspring than for female offspring $(2.8 \%, 95 \%$ CI: $1.9-4.1$ vs. $1.6 \%, 95 \%$ CI: $1.2-2.3 ; P=0.02$ ), but no differences were detected between offspring derived from SS and CONV within sex of offspring (Table 1). Mortality rates during the first 2 mo of life (excluding stillbirth) were also greater for male offspring than for female offspring $(5.0 \%, 95 \%$ CI: $3.8-6.7$ vs. $2.0 \%, 95 \%$ CI: $1.5-2.7 ; P<0.001)$, but no differences were detected between CONV and SS offspring within sex of offspring (Table 1). Mortality rates from 3 to 12 mo of age did not differ between male and female offspring $(1.9 \%, 95 \%$ CI: $1.2,3.0$ vs. $1.3 \%$, $95 \%$ CI: $0.9,1.9 ; P=0.19)$. Similarly, no difference was 
detected between CONV and SS offspring within sex of offspring (Table 1). Bull did not affect any of the mortality rates analyzed (all $P>0.22$ ).

There were no differences due to sperm treatment on survival distributions of female offspring that died during the first 2 mo of life (Figure 1a, logrank test: $P$ $=0.09$ ) or during their first year (Figure 1b, logrank test: $P=0.58$ ), nor on survival distributions of male offspring that died during the first 2 mo of age (Figure 2a, logrank test: $P=0.66$ ) or during the first year of life (Figure 2b, logrank test: $P=0.79$ ).

\section{Reproductive Performance of Female Offspring}

No differences were found between female offspring derived from CONV and SS for any of the reproductive variables analyzed (Table 2). Female offspring that had a record for a first calving event, but not a second calving event $(\mathrm{n}=469)$, included cows that died $(\mathrm{n}=65)$, were slaughtered $(\mathrm{n}=291)$, were exported after the first calving $(\mathrm{n}=26)$, and cows with no record of slaughter or death $(\mathrm{n}=87$; assumed to have been retained on-farm). Of the 469 female offspring that had only a single calving event, no differences were found between CONV and SS treatments in the proportion that died (11.6\%, $95 \%$ CI: $6.5-19.9$ vs. $14.4 \%, 95 \%$ CI: $11.2-18.5$; $P=0.47)$, were slaughtered $(66.3 \%, 95 \%$ CI: $56.1-76.5$ vs. $61.0 \%, 95 \%$ CI: $57.2-68.7 ; P=0.50)$, were exported (6.3\%, $95 \%$ CI: $2.1-12.1$ vs. $5.4 \%, 95 \%$ CI: $2.5-7.0$; $P=0.66)$, or were retained on-farm $(15.8 \%, 95 \%$ CI: $7.4-22.6$ vs. $19.3 \%, 95 \%$ CI:11.1-20.0; $P=0.68)$ after the first calving. For cows that calved more than once, the proportion of second and third calving events that occurred during the interval between January 1st to June 30th was examined to quantify the proportion that remained in a seasonal calving system. For those cows calving for a second time $(\mathrm{n}=3,004)$, there were no differences between CONV and SS treatments in the proportion of those cows with a second calving between January 1 and June 30, 2017, to start the second lactation (96.4\%, $95 \%$ CI: $94.0-97.9$ vs. $96.3 \%, 94.7-97.4 ; P$ $=0.90)$. For those cows calving for a third time $(\mathrm{n}=$ 1,854 ), there were no differences between CONV and SS treatments in the proportion of those cows with a third calving between January 1 and June 30, 2018, to start the third lactation $(91.9 \%, 95 \%$ CI: $88.0-94.5$ vs. 94.5\%, 95\% CI: $92.6-95.9 ; P=0.07)$. Bull affected age at first calving $(P<0.01$; range $732.1-745.7 \mathrm{~d})$ and calving interval $(P<0.01$; range 366.7-378.6 d) but did not affect any of the other reproductive traits analyzed $(P>0.27)$.

\section{Lactation Performance of Female Offspring}

There was no effect of sperm treatment on any of the lactation variables (Table 3 ). There was a bull effect $(P<0.001)$ on milk, fat, and protein yield during the first lactation (milk yield: range 4,938-5,639 kg; fat yield: range $214.8-237.2 \mathrm{~kg}$; protein yield: range $180.2-198.0 \mathrm{~kg}$ ), second lactation (milk yield: range $5,974-6,676 \mathrm{~kg}$; fat yield: range $260.7-282.3 \mathrm{~kg}$; protein yield: $220.5-240.6 \mathrm{~kg}$ ), and third lactation (milk yield: range 6,434-7,204 kg; fat yield: range $278.3-303.0 \mathrm{~kg}$; protein yield: range $236.4-260.2 \mathrm{~kg}$ ).

\section{Survival Analysis of Female Offspring that Calved at Least Once}

The survival distributions of female offspring that calved at least once and were derived from CONV and SS are illustrated in Figure 3; no differences were observed for survival age due to sperm treatment (logrank test: $P=0.75)$.

Table 1. Mortality rates (mean; 95\% CI in parentheses) for female and male offspring derived from AI with conventional (CONV) or X-sorted (SS) sperm

\begin{tabular}{|c|c|c|c|}
\hline Item & $\mathrm{CONV}$ & SS & $P$-value \\
\hline \multicolumn{4}{|l|}{ Females } \\
\hline Number born & 846 & 3,203 & \\
\hline Stillbirth rate $(\%)$ & $1.5(0.9-2.6)$ & $1.8(1.3-2.4)$ & 0.95 \\
\hline Mortality $2 \mathrm{mo}^{2}(\%)$ & $1.8(1.1-2.9)^{\mathrm{a}}$ & $2.2(1.7-2.9)^{\mathrm{a}}$ & 0.86 \\
\hline Mortality 3 to $12 \mathrm{mo}(\%)$ & $1.3(0.7-2.3)$ & $1.3(0.9-1.9)$ & 1.00 \\
\hline \multicolumn{4}{|l|}{ Males } \\
\hline Number born & 784 & 346 & \\
\hline Stillbirth rate ${ }^{1}(\%)$ & $2.5(1.6-3.8)$ & $3.2(1.8-5.6)$ & 0.89 \\
\hline Mortality $2 \mathrm{mo}^{2}(\%)$ & $4.5(3.2-6.3)^{\mathrm{b}}$ & $5.6(3.6-8.5)^{\mathrm{b}}$ & 0.86 \\
\hline Mortality 3 to $12 \mathrm{mo}(\%)$ & $1.8(1.0-3.0)$ & $2.0(1.0-4.0)$ & 0.99 \\
\hline
\end{tabular}

$\overline{\mathrm{a}, \mathrm{b}}$ Means differed $(P<0.01)$ between males and females.

${ }^{1}$ Stillborn $=$ dead at or within $48 \mathrm{~h}$ of birth.

${ }^{2}$ Excluding stillborn calves. 
a)

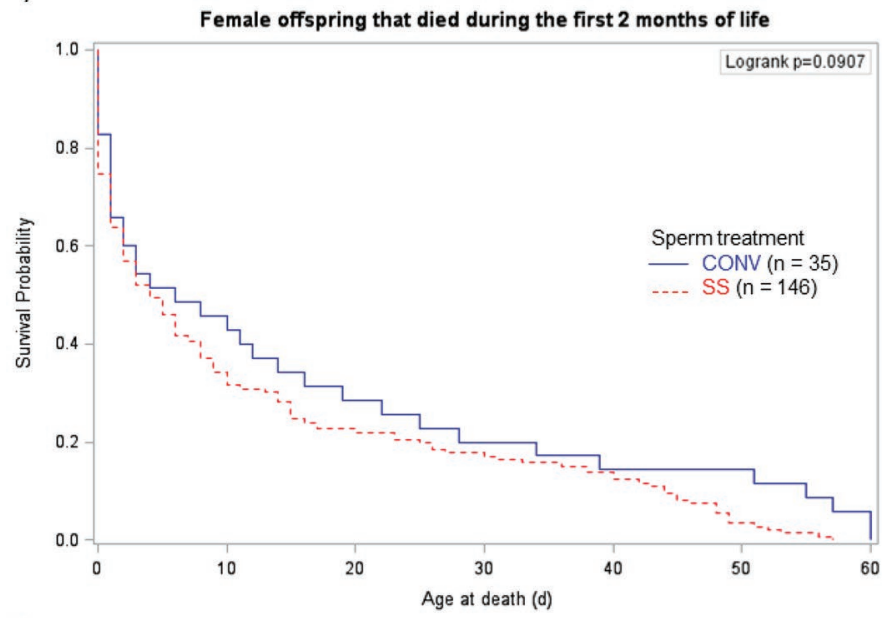

b)

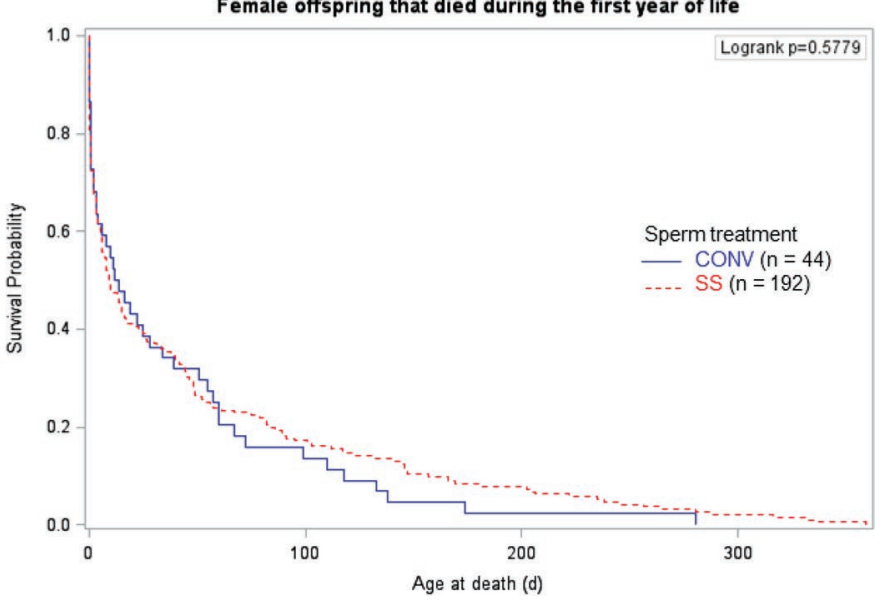

Figure 1. Survival analysis (Kaplan-Meier plot and $P$-value for the logrank test) for the interval from birth to death on-farm (age at death, in days) of female offspring that died during the first 2 mo of life (a), or during the first year (b), and were derived from AI with conventional (CONV) or X-sorted (SS) sperm.

\section{Carcass Weight at Slaughter of Male Offspring}

Carcass weight at slaughter was positively correlated with age at slaughter for both steers and young bulls ( $\mathrm{r}$ a)

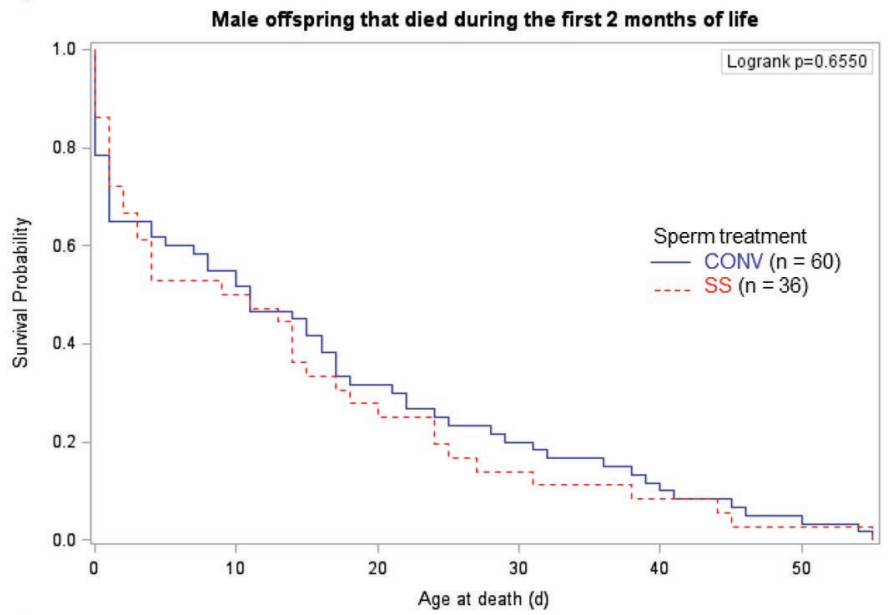

b)

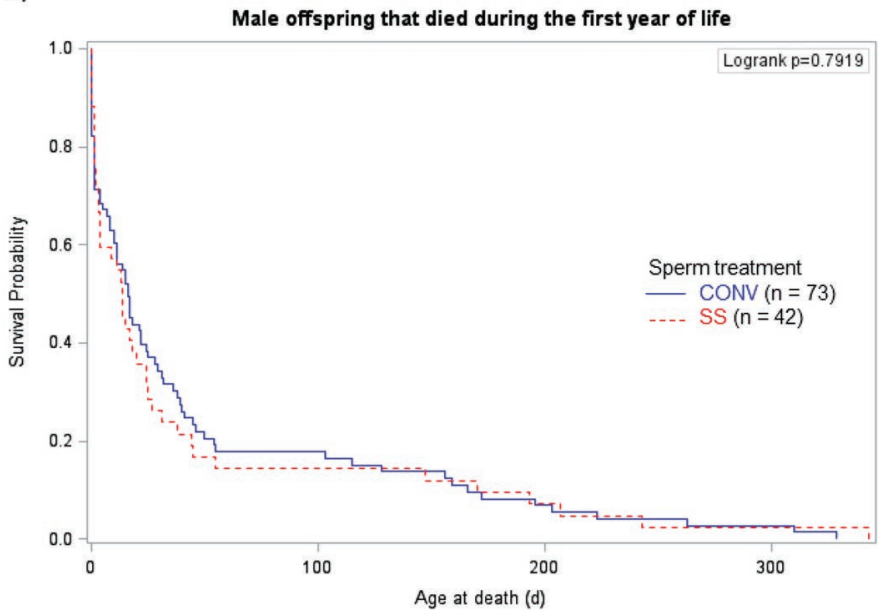

Figure 2. Survival analysis (Kaplan-Meier plot and $P$-value for the logrank test) for the interval from birth to death on-farm (age at death, in days) of male offspring that died during the first 2 mo of life (a), or during the first year (b), and were derived from AI with conventional (CONV) or X-sorted (SS) sperm.

$=0.36$ and 0.44, respectively, both $P<0.001$; Figure 4). Across all age classes, steers derived from CONV had heavier carcasses than steers derived from SS $(325.3 \mathrm{~kg}$, 95\% CI: $320.9-329.6$ vs. $318.3 \mathrm{~kg}, 95 \%$ CI: $312.3-324.3$;

Table 2. Reproductive performance (mean; $95 \%$ CI in parentheses) of female offspring derived from AI with conventional (CONV) or X-sorted (SS) sperm

\begin{tabular}{lccc}
\hline Performance & CONV & SS & $P$-value \\
\hline Reached first calving (\%) & $86.3(83.4-88.8)$ & $85.7(83.9-87.4)$ & 0.67 \\
Heifers that calved before MSD ${ }^{1}$ & $96.3(94.0-97.7)$ & $97.0(95.7-97.9)$ & 0.34 \\
Age at first calving (d) & $741.8(740.2-744.0)$ & $742.4(741.3-744.0)$ & 0.57 \\
Calved between 22 and 26 mo (\%) & $95.0(92.6-96.7)$ & $94.5(93.0-95.8)$ & 0.65 \\
Calved at > 26 mo (\%) & $5.0(3.3-7.4)$ & $5.5(4.3-7.0)$ & 0.65 \\
Heifers that calved after MSD (\%) & $3.7(2.3-6.0)$ & $3.0(2.1-4.3)$ & 0.34 \\
Reached second calving (\%) & $75.4(71.8-78.7)$ & $73.9(71.6-76.1)$ & 0.43 \\
Calving interval (d) & $373.3(370.5-376.0)$ & $371.2(369.6-372.9)$ & 0.20 \\
\hline
\end{tabular}

${ }^{1}$ Mating start date (MSD) set to May 1. 


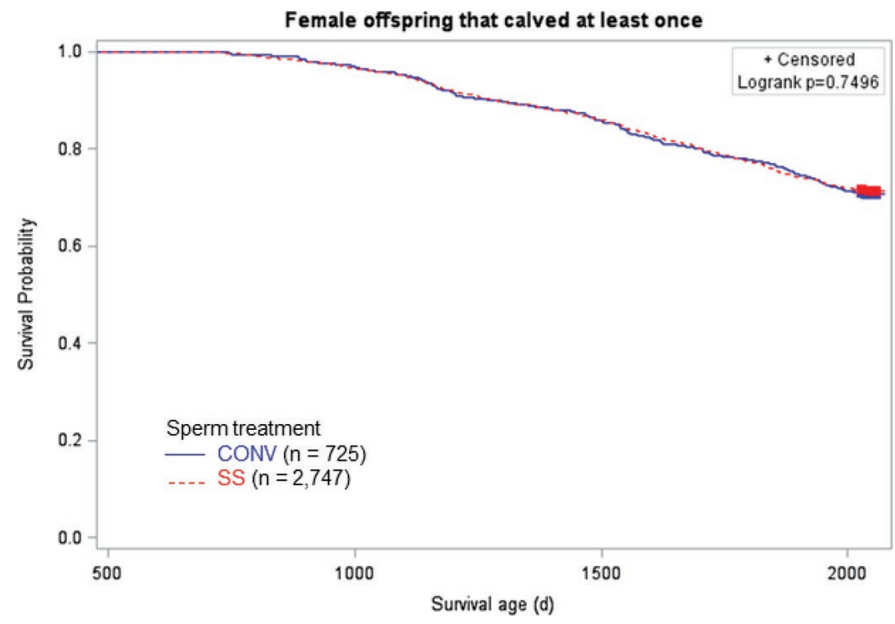

Figure 3. Survival analysis (Kaplan-Meier plot and $P$-value for the logrank test) for the interval from birth to death on-farm or slaughter (survival age, in days) of female offspring that calved at least once and were derived from AI with conventional (CONV) or X-sorted (SS) sperm. Females still alive at the time of data retrieval were rightcensored.

$P=0.035)$. However, there were no differences in carcass weight between CONV and SS steers within any of the age group categories (Figure 5a). When the analysis was restricted to only herds that reared both CONV and SS steers, steers derived from CONV tended to have heavier carcasses than steers derived from SS (322.6 kg, 95\% CI: $315.1-330.1$ vs. $314.6 \mathrm{~kg}, 95 \%$ CI: 306.3-323.0; $P=0.066$ ), but there were no differences in carcass weight between CONV and SS steers within any of the age group categories (Figure 5b).

There was no difference in carcass weight between young bulls derived from CONV or SS across age categories (317.1 kg, 95\% CI: $305.9-328.3$ vs. $307.3 \mathrm{~kg}$, 95\% CI: $292.5-322.2 ; P=0.17)$ or within age categories (Figure 6a). Similarly, when the analysis was restricted to only herds that reared both CONV and SS young bulls, there was no difference in carcass weight between young bulls derived from CONV or SS across age categories (318.4 kg, 95\% CI: $301.5-335.3$ vs. $305.8 \mathrm{~kg}$, 95\% CI: $286.3-325.3 ; P=0.12$ ) or within age categories (Figure 6b).

\section{Age at Slaughter of Steers}

The distribution of slaughter age differed (logrank test: $P=0.03$ ) between CONV and SS steers when every herd was included in the analysis, with CONV steers being slaughtered earlier than SS steers (Figure 7a). When the analysis was restricted to only herds that reared both CONV and SS steers, no difference (logrank test: $P=0.45$ ) in age at slaughter was detected (Figure 7b).

\section{Carcass Conformation and Fat Scores of Steers}

Carcass conformation and fat scores were both affected by slaughter weight (both $P<0.001$ ), but not by sperm treatment $(P=0.46$ and $P=0.79$, respectively; Table 4). The use of SS did not affect the likelihood of steers having carcass conformation scores $\geq 4$ (odds ratio: $1.17,95 \% 95 \%$ CI: $0.78-1.75)$ or fat scores $\geq 3$ (odds ratio: 0.94, 95\% CI: 0.58-1.51).

\section{DISCUSSION}

This retrospective study compared survival during the first year of life and adult performance of offspring derived from AI with X-sorted or conventional sperm processed from the same ejaculates. The main findings of the study were (1) survival during the first year of life was not different between animals that were derived from AI with X-sorted or conventional sperm; (2) male

Table 3. Projected 305-d lactation performance (mean; 95\% CI in parentheses) of female offspring derived from AI with conventional (CONV) or X-sorted (SS) sperm

\begin{tabular}{lccc}
\hline Item & CONV & SS & $P$-value \\
\hline First lactation & 521 & 1,942 & \\
$\quad$ Number & $5,256(5,159-5,353)$ & $5,195(5,113-5,276)$ & 0.10 \\
Milk yield (kg) & $228.4(224.3-232.5)$ & $226.2(222.7-229.7)$ & 0.14 \\
Fat yield (kg) & $187.1(183.8-190.4)$ & $185.3(182.4-188.1)$ & 0.12 \\
Protein yield (kg) & 455 & 1,670 & \\
Second lactation & $6,362(6,246-6,479)$ & $6,320(6,223-6,416)$ & 0.35 \\
$\quad$ Number & $269.4(264.5-274.3)$ & $270.0(266.0-274.0)$ & 0.76 \\
Milk yield (kg) & $229.0(225.1-232.9)$ & $228.4(225.1-231.7)$ & 0.69 \\
Fat yield (kg) & & & \\
Protein yield (kg) & $398(6,729-6,996)$ & $6,836(6,729-6,943)$ & 0.64 \\
Third lactation & $6,862(6,952)$ & 0.71 \\
$\quad$ Number & $289.8(284.2-295.5)$ & $290.7(286.1-295.3)$ & 0.58 \\
Milk yield (kg) & $247.5(243.0-252.1)$ & $246.5(242.7-250.2)$ & \\
Fat yield (kg) & & & \\
Protein yield $(\mathrm{kg})$ & & & \\
\hline
\end{tabular}


a)

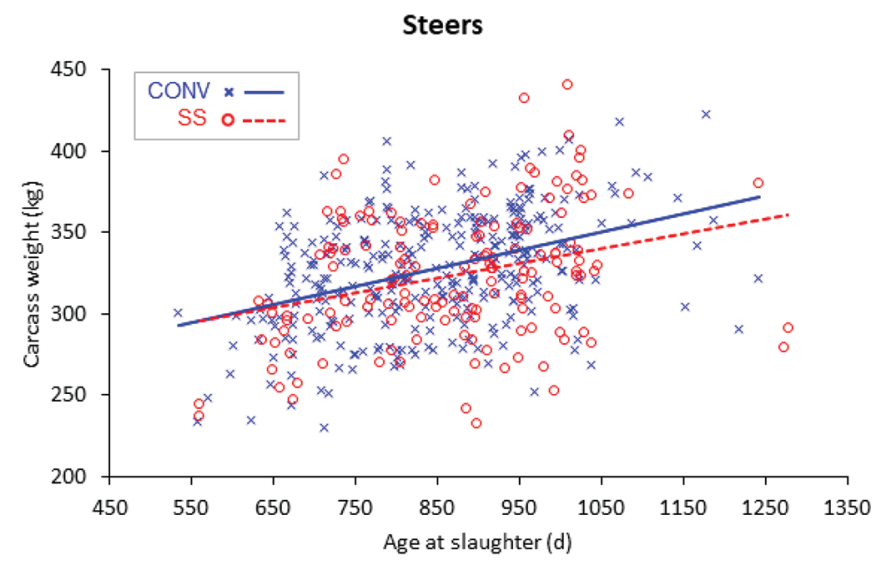

b)

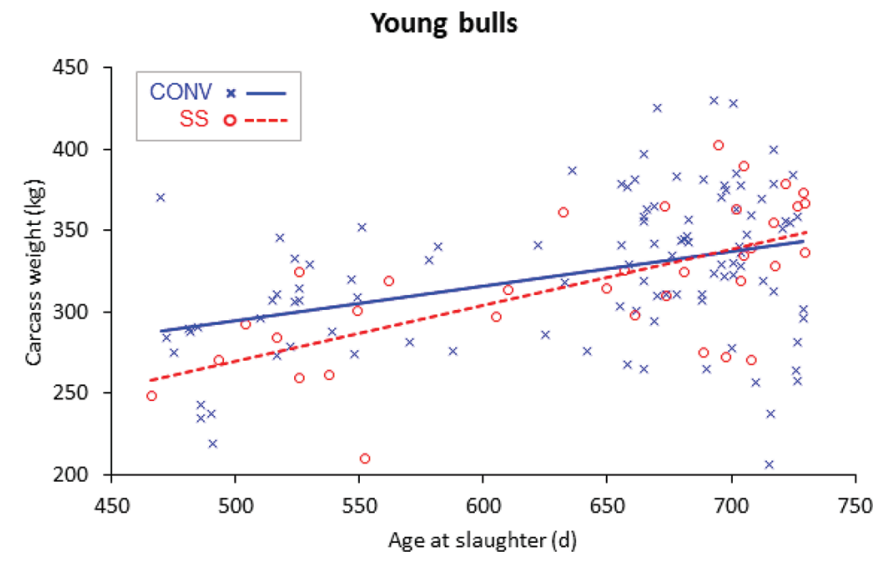

Figure 4. Scatter plots and trend lines for carcass weight at slaughter $(\mathrm{kg})$ against age at slaughter (d) for steers (a) and young bulls (b) derived from AI with conventional (CONV) or X-sorted (SS) sperm.

calves had greater mortality rates during the first 2 mo of life than female calves, independent of sperm treatment; (3) no differences existed due to sex-sorting in reproductive and lactation performance of female offspring; and (4) across all steers, those derived from AI with conventional sperm were slaughtered earlier and had greater carcass weight than steers derived from sex-sorted sperm, but the distribution of slaughter age did not differ between CONV and SS steers when the analysis was restricted to herds with steers derived from both sperm types.

No differences were observed in stillbirth rates, mortality rates, or survival during the first year of life between offspring produced after AI with conventional sperm or $\mathrm{X}$-sorted sperm derived from the same ejaculates, in agreement with Tubman et al. (2004) and Borchersen and Peacock (2009). Tubman et al. (2004) compared birth and weaning weights, calving ease score, calf a)

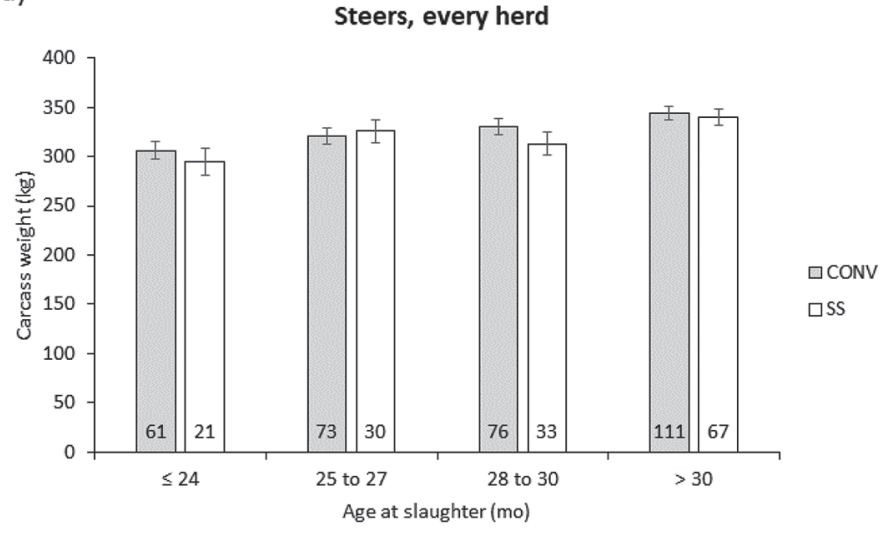

b)

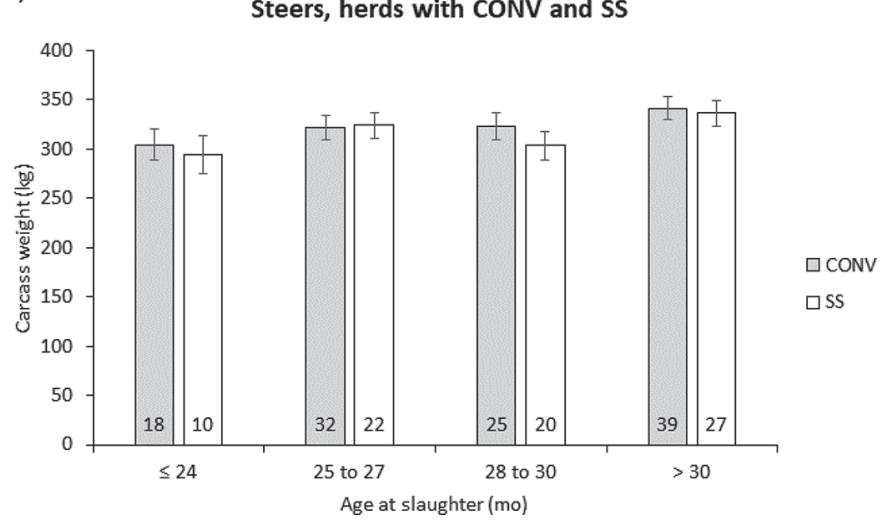

Figure 5. Mean carcass weight for steers derived from conventional (CONV) or X-sorted (SS) sperm and grouped by age at slaughter: (a) when every herd at slaughter (i.e., the last herd where steers were located before being sent to slaughter, $\mathrm{n}=278$ ) was included in the analysis, or (b) when the analysis was restricted to those herds at slaughter $(\mathrm{n}=56)$ that reared both CONV and SS steers. Mean carcass weight did not differ $(P>0.13)$ between sperm treatments within any age group. Sample sizes are displayed at the base of the bars, and the $95 \% \mathrm{CI}$ of the means are indicated by the error bars.

vigor, neonatal mortality (calves born dead or that died within $24 \mathrm{~h}$ of birth), and preweaning mortality rates of calves with different dam breeds (Holstein heifers and Angus heifers and cows), and found no difference between calves derived from X-sorted sperm and conventional sperm for any of the characteristics studied. Of note, although the data analyzed by Tubman et al. (2004) included data from calves born in 13 different field trials in 13 herds with various experimental designs (mostly concerning numbers of sperm per insemination and site of insemination), conventional and X-sorted sperm doses were processed from the same ejaculates. Similarly, stillbirth rates were not different when Holstein, Jersey, and Danish Red heifers were inseminated with sex-sorted or conventional sperm doses from the same ejaculates (Borchersen and Peacock, 2009). 
Table 4. Carcass conformation and fat scores of steers derived from AI with conventional (CONV) or X-sorted (SS) sperm

\begin{tabular}{|c|c|c|c|c|c|}
\hline Item & Number & $\begin{array}{c}\text { Mean } \\
(95 \% \text { CI })\end{array}$ & Median & Minimum & Maximum \\
\hline \multicolumn{6}{|c|}{ Conformation score ${ }^{1}$} \\
\hline CONV & 322 & $4.0(3.9-4.1)$ & 4 & 1 & 9 \\
\hline $\mathrm{SS}$ & 151 & $3.9(3.7-4.1)$ & 4 & 1 & 7 \\
\hline \multicolumn{6}{|c|}{ Fat score ${ }^{2}$} \\
\hline CONV & 322 & $3.0(2.9-3.1)$ & 3 & 1 & 4 \\
\hline SS & 151 & $3.0(2.8-3.1)$ & 3 & 1 & 5 \\
\hline
\end{tabular}

${ }^{1}$ Coded as 1 to 9 from the poorest (1) to the best (9) conformation score.

${ }^{2}$ Coded as 1 to 5 from the lowest (1) to the greatest (5) fat score.

a)

Young bulls, every herd

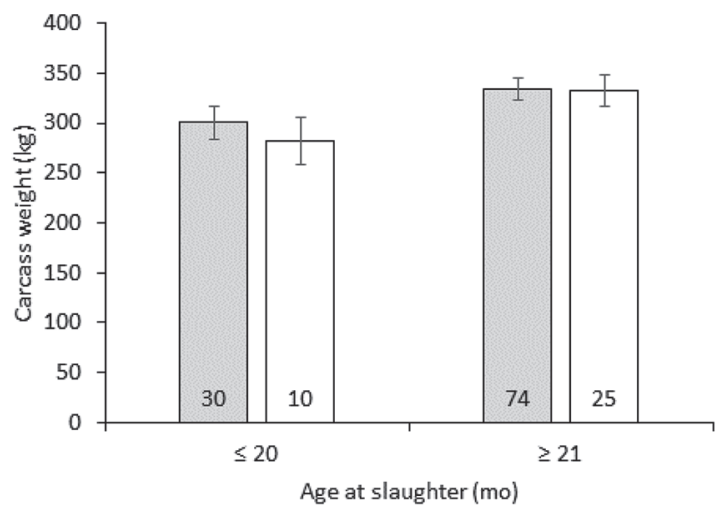

b)

Young bulls, herds with CONV and SS

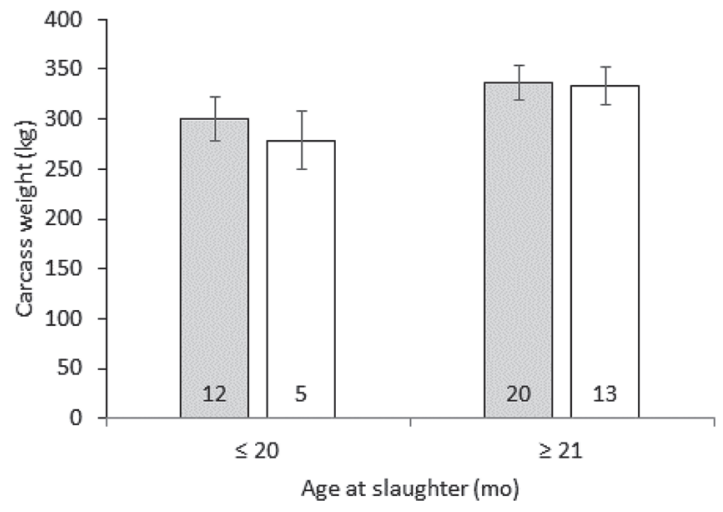

Figure 6. Mean carcass weight for young bulls derived from conventional $(\mathrm{CONV})$ or X-sorted (SS) sperm and grouped by age at slaughter: (a) when every herd at slaughter (i.e., the last herd where young bulls were located before being sent to slaughter, $\mathrm{n}=74$ ) was included in the analysis, or (b) when the analysis was restricted to those herds at slaughter $(\mathrm{n}=13)$ that reared both CONV and SS young bulls. Mean carcass weight did not differ $(P>0.38)$ between sperm treatments within any age group. Sample sizes are displayed at the base of the bars, and the 95\% CI of the means are indicated by the error bars. a)

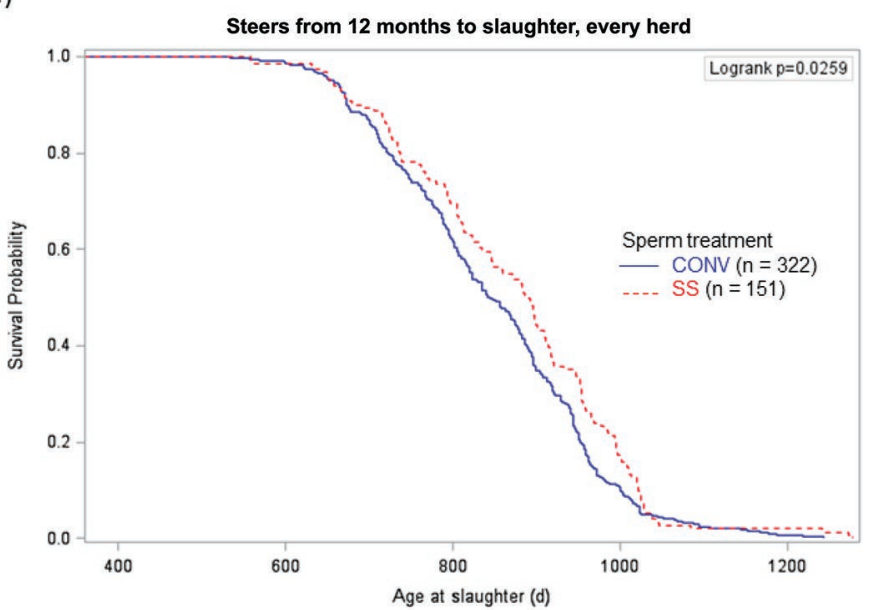

b)

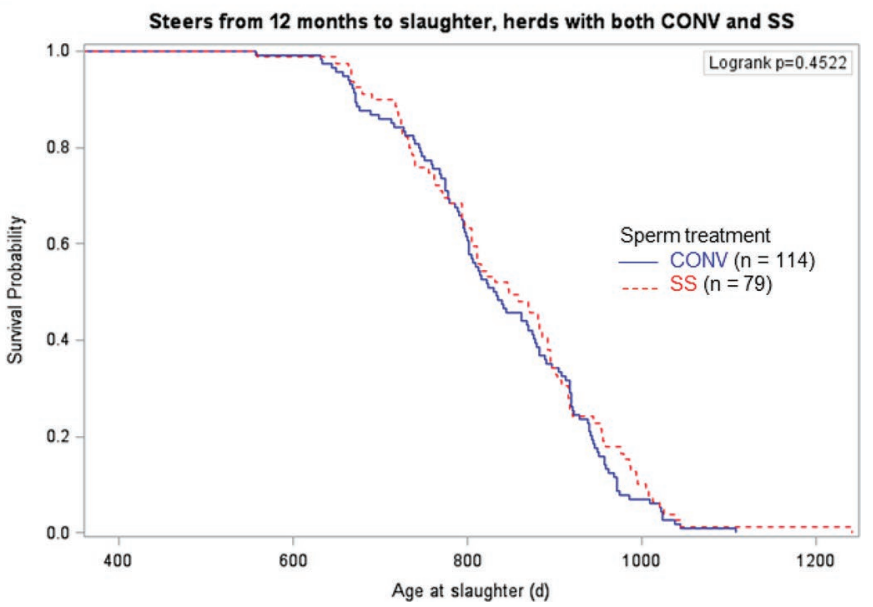

Figure 7. Survival analysis (Kaplan-Meier plot and $P$-value for the logrank test) for the interval from birth to slaughter (age at slaughter, in days) of steers derived from AI with conventional (CONV) or $\mathrm{X}$-sorted (SS) sperm: (a) when every herd at slaughter (i.e., the last herd where steers were located before being sent to slaughter, $\mathrm{n}=278$ ) was included in the analysis, or (b) when the analysis was restricted to those herds at slaughter $(\mathrm{n}=56)$ that reared both CONV and SS steers. 
In a study using Holstein heifers conducted on 2 commercial dairy herds in California, the proportion of calves born dead was greater for heifers inseminated with X-sorted sperm than for those inseminated with conventional sperm ( 8.8 vs. $3.4 \%$, respectively), independent of calf sex (Chebel et al., 2010). A tendency for a greater incidence of stillbirths was also reported among singleton calves from Holstein heifers inseminated with X-sorted sperm (X-sorted: $13.3 \%$ vs. conventional: $11.7 \% ; P=0.051$ ) in a single commercial dairy herd in Australia (Healy et al., 2013). However, these 2 studies were limited to either 1 or 2 herds, which limits the ability to extrapolate the results to all herds. In a large study exploring the use of X-sorted sperm in US Holstein herds, DeJarnette et al. (2009) reported a greater incidence of stillbirths among male calves when pregnancy was established following insemination of heifers with X-sorted sperm compared with conventional sperm (X-sorted: $19.9 \%$ vs. conventional: $12.9 \%$ ); this effect was partially explained by differences in dam age at calving. In a subsequent larger study, Norman et al. (2010) also observed the highest incidence of stillbirths among singleton male calves from heifers inseminated with X-sorted sperm (X-sorted: $15.5 \%$ vs. conventional: $10.8 \%$ ); however, this difference was not statistically significant, and no difference in stillbirth rates of male calves due to sperm treatment was observed in multiparous cows.

A common characteristic of these 4 studies (DeJarnette et al., 2009; Chebel et al., 2010; Norman et al., 2010; Healy et al., 2013) is that X-sorted and conventional sperm were not derived from the same sires. The sire used during AI can influence the occurrence of perinatal calf mortality in dairy herds (Mee et al., 2014). Furthermore, results from previous studies indicate that the decrease in field fertility of X-sorted sperm when compared with conventional sperm varied depending on the sire used, suggesting that the damaging effect of sex-sorting on sperm is sire-dependent (Frijters et al., 2009; DeJarnette et al., 2010; Healy et al., 2013; Maicas et al., 2019; Thomas et al., 2019). Therefore, comparison of X-sorted and conventional sperm produced from the same ejaculates from the same bulls, as in the present study, allows a more accurate evaluation of the effect of sex-sorting than studies that compared sex-sorted and conventional sperm from different bulls, where a sire effect cannot be discounted.

We observed greater mortality rates during the first 2 mo of life for male calves than for female calves, independent of sperm treatment. This may be related to a greater incidence of dystocia in male calves and its longterm consequences for calf health, as male calves are, on average, heavier at birth than female calves (Sieber et al., 1989; Johanson and Berger, 2003; Tubman et al.,
2004). Johanson and Berger (2003) found birth weight to be a strong predictor of dystocia, with a 1-kg increase in birth weight resulting in a $13 \%$ increase in the odds of dystocia. Greater incidence of dystocia has been reported for male calves (Tubman et al., 2004; Norman et al., 2010). Dystocia can have a negative effect on calf health beyond the first $48 \mathrm{~h}$ after parturition and affect calf survival during the following month (Lombard et al., 2007; Barrier et al., 2013). In addition, male dairy calves are at risk of receiving less attention and care than female calves during this crucial period of rearing because they have a lower economic value (Renaud et al., 2017; Shivley et al., 2019).

None of the aforementioned studies that evaluated offspring characteristics after using X-sorted sperm for AI (Tubman et al., 2004; Borchersen and Peacock, 2009; DeJarnette et al., 2009; Chebel et al., 2010; Norman et al., 2010; Healy et al., 2013) or MOET (Mikkola et al., 2015) investigated whether sex-sorting of sperm had effects on adult performance. Siqueira et al. (2017) reported adverse effects on lactation performance during the first lactation for heifers born after IVP when reverse X-sorted sperm was used, but not when conventional sperm was used. Unlike the current study, however, the data analyzed by Siqueira et al. (2017) made it difficult to draw conclusions related only to the effect of sperm sex-sorting. For example, neither dams nor sires were randomly assigned to reproductive technique, thus parental effects and bias due to the preferential use of any of the reproductive techniques cannot be discounted. Moreover, sperm was sex-sorted after cryopreservation (reverse X-sorted sperm), and was always used in association with IVP, which by itself has been associated with loss of genomic imprinting (Chen et al., 2015), abnormal fetoplacental development (Miles et al., 2004; Farin et al., 2006; Bloise et al., 2014), and increased neonatal mortality (Bonilla et al., 2014).

In the present study, we evaluated adult performance of offspring born after AI with conventional or X-sorted sperm processed from the same ejaculates, which had been randomly assigned to inseminate dams in a large cohort of herds. We found no differences due to sexsorting in survival or reproductive and lactation performance during the first, second, or third lactation of female offspring. Overall, steers derived from AI with CONV sperm were slaughtered earlier and had greater carcass weight than SS steers, but it should be noted that this finding may be an artifact of the relatively small total number of steers, and the relatively large number of rearing herds in the study. Hence, there were differences in steer husbandry and nutritional management depending on the rearing herd. This was supported by the observation that the distribution of 
slaughter age did not differ between CONV and SS steers when the analysis was restricted to herds that had steers derived from both sperm types. An experiment using steers derived from conventional or X-sorted sperm from split ejaculates, exposed to similar nutrition and herd management practices, and with regular BW measurements at the same ages, is required to clarify whether there is a true difference in $\mathrm{BW}$ gain due to the sex-sorting process.

In conclusion, the results provide no evidence of differences in survival during the first year of life between offspring derived from conventional or X-sorted sperm, or for any of the reproductive and lactation performance characteristics studied between female offspring derived from conventional or X-sorted sperm. Further controlled research is required to compare growth and carcass characteristics of male offspring derived from conventional and X-sorted sperm.

\section{ACKNOWLEDGMENTS}

The authors gratefully acknowledge the Irish Cattle Breeding Federation (Bandon, Co. Cork, Ireland) for the work and assistance in extracting and collating the data. Clio Maicas was supported by a Teagasc Walsh Fellowship, and Ian Hutchinson was supported by a Teagasc Post-doctoral Fellowship. The authors have stated no conflicts of interest.

\section{REFERENCES}

Barrier, A. C., M. J. Haskell, S. Birch, A. Bagnall, D. J. Bell, J. Dickinson, A. I. Macrae, and C. M. Dwyer. 2013. The impact of dystocia on dairy calf health, welfare, performance and survival. Vet. J. 195:86-90. https://doi.org/10.1016/j.tvj1.2012.07.031.

Bloise, E., S. K. Feuer, and P. F. Rinaudo. 2014. Comparative intrauterine development and placental function of ART concepti: Implications for human reproductive medicine and animal breeding. Hum. Reprod. Update 20:822-839. https://doi.org/10.1093/ humupd/dmu032.

Bonilla, L., J. Block, A. C. Denicol, and P. J. Hansen. 2014. Consequences of transfer of an in vitro-produced embryo for the dam and resultant calf. J. Dairy Sci. 97:229-239. https://doi.org/10 $.3168 / \mathrm{jds} .2013-6943$.

Borchersen, S., and M. Peacock. 2009. Danish A.I. field data with sexed semen. Theriogenology 71:59-63. https://doi.org/10.1016/j .theriogenology.2008.09.026.

Chebel, R. C., F. S. Guagnini, J. E. Santos, J. P. Fetrow, and J. R. Lima. 2010. Sex-sorted semen for dairy heifers: Effects on reproductive and lactational performances. J. Dairy Sci. 93:2496-2507. https://doi.org/10.3168/jds.2009-2858.

Chen, Z., D. E. Hagen, C. G. Elsik, T. Ji, C. J. Morris, L. E. Moon, and R. M. Rivera. 2015. Characterization of global loss of imprinting in fetal overgrowth syndrome induced by assisted reproduction. Proc. Natl. Acad. Sci. USA 112:4618-4623. https://doi.org/ 10.1073/pnas.1422088112.

DeJarnette, J. M., C. R. McCleary, M. A. Leach, J. F. Moreno, R. L. Nebel, and C. E. Marshall. 2010. Effects of 2.1 and $3.5 \times 10^{6}$ sexsorted sperm dosages on conception rates of Holstein cows and heifers. J. Dairy Sci. 93:4079-4085. https://doi.org/10.3168/jds $.2010-3181$.
DeJarnette, J. M., R. L. Nebel, and C. E. Marshall. 2009. Evaluating the success of sex-sorted semen in US dairy herds from on farm records. Theriogenology 71:49-58. https://doi.org/10.1016/j theriogenology.2008.09.042

Duranthon, V., and P. Chavatte-Palmer. 2018. Long term effects of ART: What do animals tell us? Mol. Reprod. Dev. 85:348-368. https://doi.org/10.1002/mrd.22970.

EU. 2013. Regulation (EU) No 1308/2013 of the European Parliament and of the Council of 17 December 2013 establishing a common organisation of the markets in agricultural products and repealing Council Regulations (EEC) No 922/72, (EEC) No 234/79, (EC) No $1037 / 2001$ and (EC) No 1234/2007. Annex IV. http://data .europa.eu/eli/reg/2013/1308/oj.

Farin, P. W., J. A. Piedrahita, and C. E. Farin. 2006. Errors in development of fetuses and placentas from in vitro-produced bovine embryos. Theriogenology 65:178-191. https://doi.org/10.1016/j .theriogenology.2005.09.022.

Frijters, A. C., E. Mullaart, R. M. Roelofs, R. P. van Hoorne, J. F. Moreno, O. Moreno, and J. S. Merton. 2009. What affects fertility of sexed bull semen more, low sperm dosage or the sorting process? Theriogenology 71:64-67. https://doi.org/10.1016/j .theriogenology.2008.09.025.

Garner, D. L., K. M. Evans, and G. E. Seidel. 2013. Sex-sorting sperm using flow cytometry/cell sorting. Pages 279-295 in Spermatogenesis: Methods and Protocols. D. T. Carrell and K. I. Aston, ed. Humana Press, Totowa, NJ.

Garner, D. L., B. L. Gledhill, D. Pinkel, S. Lake, D. Stephenson, M. A. Van Dilla, and L. A. Johnson. 1983. Quantification of the X- and Y-chromosome-bearing spermatozoa of domestic animals by flow cytometry. Biol. Reprod. 28:312-321. https://doi.org/10.1095/ biolreprod28.2.312.

Healy, A. A., J. K. House, and P. C. Thomson. 2013. Artificial insemination field data on the use of sexed and conventional semen in nulliparous Holstein heifers. J. Dairy Sci. 96:1905-1914. https:// doi.org/10.3168/jds.2012-5465.

Hutchison, J.M., and D. Bickhart. 2016. Sexed-semen usage for Holstein AI in the United States. J. Anim. Sci. 94(Suppl. 5):180. https://doi.org/10.2527/jam2016-0372.

Johanson, J., and P. Berger. 2003. Birth weight as a predictor of calving ease and perinatal mortality in Holstein cattle. J. Dairy Sci. 86:3745-3755. https://doi.org/10.3168/jds.S0022-0302(03)73981 -2 .

Lombard, J. E., F. B. Garry, S. M. Tomlinson, and L. P. Garber. 2007. Impacts of dystocia on health and survival of dairy calves. J. Dairy Sci. 90:1751-1760. https://doi.org/10.3168/jds.2006-295.

Maicas, C., I. A. Hutchinson, J. Kenneally, J. Grant, A. R. Cromie, P. Lonergan, and S. T. Butler. 2019. Fertility of fresh and frozen sex-sorted semen in dairy cows and heifers in seasonal-calving pasture-based herds. J. Dairy Sci. 102:10530-10542. https://doi .org/10.3168/jds.2019-16740.

Mee, J. F., C. Sánchez-Miguel, and M. Doherty. 2014. Influence of modifiable risk factors on the incidence of stillbirth/perinatal mortality in dairy cattle. Vet. J. 199:19-23. https://doi.org/10.1016/ j.tvjl.2013.08.004.

Mikkola, M., M. Andersson, and J. Taponen. 2015. Transfer of cattle embryos produced with sex-sorted semen results in impaired pregnancy rate and increased male calf mortality. Theriogenology 84:1118-1122. https://doi.org/10.1016/j.theriogenology.2015 .06 .012 .

Miles, J. R., C. E. Farin, K. F. Rodriguez, J. E. Alexander, and P. W. Farin. 2004. Angiogenesis and morphometry of bovine placentas in late gestation from embryos produced in vivo or in vitro. Biol. Reprod. 71:1919-1926. https://doi.org/10.1095/biolreprod .104.031427.

Norman, H. D., J. L. Hutchison, and R. H. Miller. 2010. Use of sexed semen and its effect on conception rate, calf sex, dystocia, and stillbirth of Holsteins in the United States. J. Dairy Sci. 93:38803890. https://doi.org/10.3168/jds.2009-2781.

Ortiz, W. G., J. A. Rizo, L. R. Carvalheira, B. M. S. Ahmed, E. Estrada-Cortes, B. R. Harstine, J. J. Bromfield, and P. J. Hansen. 2019. Effects of intrauterine infusion of seminal plasma at artificial 
insemination on fertility of lactating Holstein cows. J. Dairy Sci. 102:6587-6594. https://doi.org/10.3168/jds.2019-16251.

Ramos-Ibeas, P., S. Heras, I. Gomez-Redondo, B. Planells, R. Fernandez-Gonzalez, E. Pericuesta, R. Laguna-Barraza, S. Perez-Cerezales, and A. Gutierrez-Adan. 2019. Embryo responses to stress induced by assisted reproductive technologies. Mol. Reprod. Dev. 86:1292-1306. https://doi.org/10.1002/mrd.23119.

Renaud, D. L., T. F. Duffield, S. J. LeBlanc, D. B. Haley, and D. F. Kelton. 2017. Management practices for male calves on Canadian dairy farms. J. Dairy Sci. 100:6862-6871. https://doi.org/10.3168/ jds.2017-12750.

Shivley, C. B., J. E. Lombard, N. J. Urie, D. M. Weary, and M. A. G. von Keyserlingk. 2019. Management of preweaned bull calves on dairy operations in the United States. J. Dairy Sci. 102:4489-4497. https://doi.org/10.3168/jds.2018-15100.

Sieber, M., A. Freeman, and D. Kelley. 1989. Effects of body measurements and weight on calf size and calving difficulty of Holsteins. J. Dairy Sci. 72:2402-2410. https://doi.org/10.3168/jds.S0022 -0302(89) 79373-5.

Siqueira, L. G. B., S. Dikmen, M. S. Ortega, and P. J. Hansen. 2017. Postnatal phenotype of dairy cows is altered by in vitro embryo production using reverse X-sorted semen. J. Dairy Sci. 100:58995908. https://doi.org/10.3168/jds.2016-12539.

Thomas, J. M., J. W. C. Locke, R. C. Bonacker, E. R. Knickmeyer, D. J. Wilson, R. Vishwanath, A. M. Arnett, M. F. Smith, and D.
J. Patterson. 2019. Evaluation of SexedULTRA 4M ${ }^{\mathrm{TM}}$ sex-sorted semen in timed artificial insemination programs for mature beef cows. Theriogenology 123:100-107. https://doi.org/10.1016/j .theriogenology.2018.09.039.

Tubman, L. M., Z. Brink, T. K. Suh, and G. E. Seidel Jr.. 2004. Characteristics of calves produced with sperm sexed by flow cytometry/ cell sorting. J. Anim. Sci. 82:1029-1036. https://doi.org/10.2527/ 2004.8241029x.

Viana, J. H. M., A. C. S. Figueiredo, R. L. R. Gonçalves, and L. G. B. Siqueira. 2018. A historical perspective of embryo-related technologies in South America. Anim. Reprod. 15(Suppl. 1):963-970. https://doi.org/10.21451/1984-3143-AR2018-0016.

Vishwanath, R., and J. F. Moreno. 2018. Review: Semen sexing-Current state of the art with emphasis on bovine species. Animal 12(Suppl. 1):s85-s96. https://doi.org/10.1017/ S1751731118000496.

\section{ORCIDS}

C. Maicas (ํ) https://orcid.org/0000-0002-9315-1443

P. Lonergan (ㄴ) https://orcid.org/0000-0001-5598-5044

S. T. Butler @ https://orcid.org/0000-0003-1542-8344 